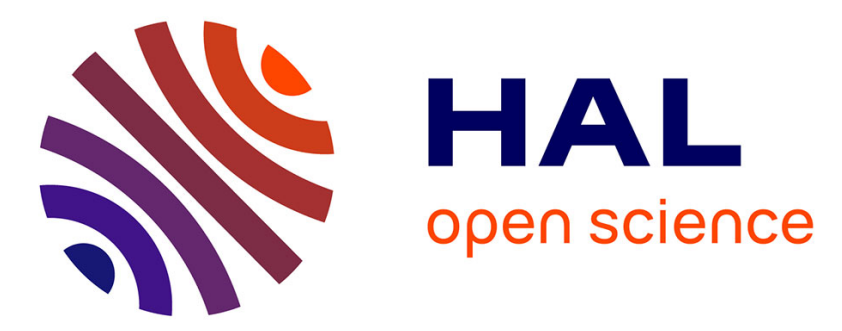

\title{
Air pollution, a rising environmental risk factor for cognition, neuroinflammation and neurodegeneration: The clinical impact on children and beyond
}

L. Calderón-Garcidueñas, Emmanuelle Leray, P. Heydarpour, R. Torres-Jardón, J Reis

\section{To cite this version:}

L. Calderón-Garcidueñas, Emmanuelle Leray, P. Heydarpour, R. Torres-Jardón, J Reis. Air pollution, a rising environmental risk factor for cognition, neuroinflammation and neurodegeneration: The clinical impact on children and beyond. Revue Neurologique, 2016, 172 (1), pp.69-80. 10.1016/j.neurol.2015.10.008 . hal-01255833

HAL Id: hal-01255833

https://hal-univ-rennes1.archives-ouvertes.fr/hal-01255833

Submitted on 18 Jan 2016

HAL is a multi-disciplinary open access archive for the deposit and dissemination of scientific research documents, whether they are published or not. The documents may come from teaching and research institutions in France or abroad, or from public or private research centers.
L'archive ouverte pluridisciplinaire HAL, est destinée au dépôt et à la diffusion de documents scientifiques de niveau recherche, publiés ou non, émanant des établissements d'enseignement et de recherche français ou étrangers, des laboratoires publics ou privés. 
A rising environmental risk factor: air pollution.

Cognition, neuroinflammation, and neurodegeneration: the clinical impact on children and beyond.

Lilian Calderón-Garcidueñas MA, MD, PhD ${ }^{1,2}$, Emmanuelle Leray ${ }^{3}$, Pouria Heydarpour MD, $\mathrm{MPH}^{4}$, Ricardo Torres-Jardón $\mathrm{PhD}^{5}$, Jacques Reis MD, ${ }^{6}$

${ }^{1}$ The University of Montana, Missoula, MT, 59812, USA

${ }^{2}$ Universidad del Valle de México, México DF 04850

${ }^{3}$ EHESP Sorbonne Paris Cité, Rennes, France

${ }^{4} \mathrm{MS}$ research center, Neuroscience Institute, Tehran University of Medical Sciences, Tehran, Iran

${ }^{5}$ Centro de Ciencias de la Atmósfera, Universidad Nacional Autónoma de México, Mexico City, México.

${ }^{6}$ Service de Neurologie (Prof. Tranchant), Centre hospitalier Universitaire, Hôpital de Hautepierre 1 avenue Molière 67200 Strasbourg, Club de Neurologie de l'Environnement, France

\section{Contact Information:}

Jacques Reis 67 Rue de Graefinthal 57200 Sarreguemines, France, Jacques.reis@wanadoo.fr

Conflict of Interest Disclosures: None reported

\section{Grant Support: None}

Key words: neurodegeneration, children' brain development, Alzheimer disease, Parkinson Disease, Multiple sclerosis, air pollution, particulate matter, ozone, nitrogenous oxides gases 


\begin{abstract}
Air pollution (indoor and outdoor air) is a major issue in public health as epidemiological studies haven pointed to the numerous detrimental health consequences (notably, respiratory and cardiovascular pathology). In the last fifteen years, air pollution has also been considered as a potent environmental risk factor for neurological diseases and neuropathology. In this review, the authors examine the impact of air pollution on children's brain development and its clinical, cognitive, brain structural and metabolic consequences. Long-term potential consequences for adults' brain and effects on multiple sclerosis are also discussed. One challenge is assessing lifetime exposures to outdoor and indoor environments, including occupational exposures: how much, for how long and what type. The diffuse neuroinflammation, the damage to the neurovascular unit, and the production of auto-antibodies to neural and tight junction proteins are worrisome findings in children chronically exposed to concentrations above current standards for ozone and fine particulate matter $\left(\mathrm{PM}_{2.5}\right)$ and may constitute significant risk factors for the development of Alzheimer's disease later in life. At last, we review data supporting the role of air pollution as risk factor in multiple sclerosis, pointing on the effect of Particulate Matter (PM 10) and nitrogenous oxides.
\end{abstract}

\title{
Résumé
}

La pollution de l'air (ambiant et atmosphérique) est un problème majeur de Santé Publique comme le montrent les études épidémiologiques illustrant les nombreuses conséquences sanitaires (notamment respiratoires et cardio-circulatoires). Au cours des quinze dernières années, la pollution de l'air a été reconnue comme un facteur de risque environnemental important dans les affections neurologiques. Dans cette revue les auteurs évaluent l'impact de la pollution de l'air sur le développement cérébral de l'enfant avec ses conséquences cliniques, cognitives, mais aussi structurales et métaboliques. Les conséquences potentielles à long terme sur le cerveau des adultes sont ensuite abordées. 
L'évaluation, vie entière, des expositions à des polluants ambiants et extérieurs constitue un réel défi : à quelle dose, pendant combien de temps, par quel type. Le constat, chez des enfants exposés de manière chronique à de l'Ozone et aux particules fines (PM2.5) à des concentrations au-delà des normes habituelles, d'une neuroinflammation diffuse, de lésions de l'unité neurovasculaire, de la production d'anticorps dirigés contre les protéines neuronales et des jonctions serrées, est particulièrement préoccupant. En effet, ces modifications pourraient être un facteur de risque du développement ultérieur d'une maladie d'Alzheimer. Enfin, sont analysées des données qui permettent de considérer la pollution de l'air (et notamment les particules fines (PM 10) et les Oxydes d'azote) comme un nouveau facteur de risque de la sclérose en plaques.

\section{$\underline{\text { Article Outline }}$}

1. Introduction

2. Assessing air pollutant exposures

3. Brain effects of polluted air in children

31. Cognition and brain structural effects

Polycyclic aromatic hydrocarbons (PAHs), the ubiquitous pollutants

32. Neuroinflammatory and neurodegenerative changes

33. Breakdown of epithelial and endothelial barriers

34. Brainstem pathology

4. Alzheimer's and Parkinson's diseases and air pollution

The key role of APOE 4

5. The need for neuroprotection in high-risk children and young adults 
6. Air pollution as risk factor in multiple sclerosis

6.1. Air pollution as a risk factor in MS

6.2 Air pollutants play a role in neuroinflammation

\subsection{Future directions}

\section{Conclusion}

\section{Introduction}

Environmental Neurology (EN) is a new field of practice and research[1] dedicated to a global, comprehensive and translational study of the action of Environment on Man. Albert Einstein defined environment as "everything but me". Environmental Medicine uses four approaches for the study of environmental factors affecting humans: approach by agents (e.g. chemicals), by milieu (e.g. a water, air), by population (e.g. children) and of course by pathologies. EN links neurology with public health issues. WHO define air pollution as a "contamination of the indoor or outdoor environment by any chemical, physical or biological agent that modifies the natural characteristics of the atmosphere" (http://www.who.int/topics/air pollution/en/).

With the industrial revolution in the Eighty-century, the air pollution increased dramatically. Combustion of fossil energies (coal, coke, gasoline and diesel fuel), needed to power industries, transportations and housing, is responsible for the release for many hundreds of contaminants into the atmosphere. However the mixture of the air pollutants changed in the twenty-century; oil and diesel replaced coal and became the major energy sources used in expending cities (urbanization) in the western countries. By the sixties and seventies two major types of mixtures were recognized the London-type smog (linked with fossil fuel combustion and PM emissions) and the Los Angeles-type smog or photochemical oxidant pollution whose main compounds are ozone and the secondary aerosols (sulfate and nitrate oxides)[2]. 
Nowadays, only some atmospheric air pollutants are monitored, depending on their health effects and regulations in the different countries, e.g. ozone, sulphur dioxide, carbon monoxide, nitrogen dioxide, lead and particulate matter (PM). The other air contaminants referred as hazardous pollutants should also be measured because highly neurotoxic chemicals are included e.g. volatile organic compounds (benzene, formaldehyde, tri- and tetrachloroethylene, toluene, polycyclic aromatic hydrocarbons PAHs etc.) and metals (lead, manganese, iron, mercury, arsenic, cadmium, cobalt, etc.)[3].

The neurological effects associated with sustained exposures to concentrations of outdoor air pollutants above the current international air quality standards are an important issue for the millions of people living in megacities around the world, including Mexico City Metropolitan Area (MCMA), Tehran and Paris, for example. Paris residents are exposed to high concentrations of particulate matter (PM), nitrogen oxide (NOx), and PAHs and share with residents in New York, Toronto, Salt Lake City, Fairbanks AK, Provo, UT, Los Angeles-South Coast Air Basin, CA, Nogales, AZ and MCMA their main sources of pollution: transport, industry and heating. Airborne PM varies in its physical and chemical composition, source and particle size. PM including PM $_{10}$, coarse particles larger than $2.5 \mu \mathrm{m}$ and smaller than $10 \mu \mathrm{m}, \mathrm{PM}_{2.5}$, fine particles larger than $100 \mathrm{~nm}$ and smaller than $2.5 \mu \mathrm{m}$ and ultrafine $\mathrm{PM}<100 \mathrm{~nm}$ ) and their components, are key pollutants in European cities.

This review will focus on three topics, the detrimental impact of environmental factors upon the brain in development, its long-term potential neurodegenerative consequences and air pollution as a risk factor in multiple sclerosis (MS). We will discuss how to evaluate air pollutant exposures and concentration estimates, relevant publications, and the uncertainties and expected long-term brain effects on urban residents. 


\section{Assessing air pollutant exposures in our patients}

The first issue we faced in evaluating patient's exposures to air pollutants is: how much, for how long and what type? And since most people are exposed to complex mixtures of air pollutants from different sources-indoors and outdoors and occupational exposures-all available information has to be considered. Meteorological conditions, including precipitation, sunshine, ambient temperatures, etc., are included in the search for environmental factors associated with central nervous system (CNS) effects. Traffic-related air pollutants are a prime exposure source in urbanites and we know the highest exposures are seen near busy roads. Automated geocoding methods are being used to estimate exposures and factors such as road edge and road centerline, road curvature, road width and the presence of ramps, can substantially alter exposure estimates near roads because of the spatial gradients of traffic-related pollutant concentrations[2]. Land-use regression models, linedispersion models, proximity-based assessments, personal monitors along with interquartile-range increases in air pollutant levels, inclusion of several lag day evaluations, peak seasonal associations are used to identify key air pollutants and exposure windows conferring the greatest risk. The primary objectives of neurological endpoints and air pollution exposures will depend on the analysis of the neurological variables and if the effects we are interested relate to short or chronic air pollution exposures. Thus, a time-stratified case-crossover design will be suitable to investigate associations between acute exposures to PM and gaseous air pollutants and an acute event such as stroke, while evaluating the risk of Alzheimer's development will require years of air pollution evaluations [3-5]. Moreover, since air pollution levels are generally believed to be higher in deprived areas, keeping in mind air pollution inequalities and ways of transportation at national, regional and city level have to be contemplated [6]. Platt et al., showed that elevated PM levels can be a consequence of 'asymmetric pollution' from two-stroke scooters, that although constitute a small fraction of the fleet, can dominate urban vehicular pollution through organic aerosol and aromatic emission factors up to thousands of times higher than from other vehicle classes [7]. 
Also important is the fact that air pollutant concentrations can have an impact upon a neurological endpoint without necessarily going over the accepted air quality standards. A good example is the association between low-level $\mathrm{O}_{3}$ exposure and ischaemic stroke in a high vascular risk subgroup demonstrated in a case-crossover study in Nice, France [8].

Evaluation of air pollutant exposures in private practice or in a hospital setting should include childhood exposures (including parents occupations), a full occupational and residential history, along with hobbies, transportation means, tobacco exposures $\left(1^{\text {st }}, 2^{\text {nd }}\right.$ and $3^{\text {rd }}$ hand exposures $)$, cooking habits, type of stove, heating sources, type of housing, distance to busy roads and highways and fixed sources of air pollutants. In long-term studies, the ability to have good spatial exposure assessments and a proper control of confounders related to air pollution and the neurological endpoint, like socioeconomic status (SES) is key.

\section{Brain effects of polluted air on children.}

Children's prime health and optimal brain development require clean air. Brain effects associated with intra and extrauterine air pollution exposures in children are not broadly recognized. Pediatric health providers acknowledge the impact of intrauterine factors, parent-child interactions, and cognitive stimulation, maternal socioeconomic status during pregnancy, child's nutrition and exposure to complex learning stimuli, all vital for brain development; unfortunately, air pollution brain effects rooted in intrauterine life and childhood are not generally acknowledged. A crucial point to remember is that overall children and adults are exposed to complex mixtures of air pollutants and although some correlations can be done with specific pollutants, it is extremely difficult to pin point specific CNS effects to specific environmental pollutants. 


\section{Cognition effects and brain structural changes}

Prenatal and postnatal exposures to complex mixtures of air pollutants produce adverse effects on neurodevelopment in early childhood, teen and young adulthood years. Cognition effects have been associated to a wide range of pollutants from tobacco, black carbon (a marker for traffic particles), wood smoke exposures in cooking practices, to common urban air pollutants across the world [917].

Black carbon exposures and cognition were explored in 202 Boston, Massachusetts, children 9.7 \pm 1.7 years, in a prospective birth cohort study (1986-2001) [13]. Black carbon (per interquartilerange increase) was associated with decreases in the vocabulary, matrices and composite intelligence quotient scores of the Kaufman Brief Intelligence Test and with decreases on the visual subscale and general index of the Wide Range Assessment of Memory and Learning. Higher levels of black carbon predicted decreased cognitive function across assessments of verbal and nonverbal intelligence and memory constructs.

Environmental tobacco smoke (ETS) exposure negatively impacts cognitive abilities among U.S. children and adolescents 6-16 years of age [12]. Significant inverse relationships between serum cotinine and scores on reading, math, and block design, but not digit span (Wechsler Intelligence Scale for Children-III) were observed in exposed children even at low levels of exposure. The combination of prolonged exposure to traffic-related air pollution (NO2, an indicator for trafficrelated air pollution) as well as noise also adversely affects digit memory span in 9-11 year olds living around the Schiphol-Amsterdam Airport [14]. Structural brain changes are seen in highly exposed urban clinically healthy children when compared to clean air controls. Fifty six percent of healthy Mexico City children versus controls showed prefrontal white matter hyperintensities (WMH) by magnetic resonance imaging (MRI) and similar lesions were observed in healthy young dogs (57\%) living in an animal facility in the same neighborhood as the children's [9]. 
Critical to this review, Mexico City dogs had WMH frontal lesions with vascular subcortical pathology associated with neuroinflammation, gliosis, and ultrafine particle deposition. The presence of WMH in urban children is important because childhood SES predicts the burden of brain WMH in older adults, establishing a potential link with dementia and stroke in later years [18]. The presence or absence of WMH is critical for early identification of children at risk in the clinical setting [10]. WMH+ positively correlate with a profile of cytokines involved in resolution of inflammation, immunoregulation, and tissue remodeling. Mexico City children with $\mathrm{WMH}+$ responded to the air pollution-associated brain volumetric alterations with white and grey matter volume increases in temporal, parietal, and frontal regions and better cognitive performance compared to MC children with WMH-. Thus, a complex modulation of cytokines and chemokines influences children's brain structural and volumetric responses and cognitive correlates resulting from environmental pollution exposures. Most recent investigations are implicating genetic factors, in particular, emerging evidence shows APOE genotype may play a pivotal role in the cognitive responses of urban children [19].This is very relevant to future increased risk of Alzheimer disease development. Indeed, the APOE 4 allele is the most prevalent genetic risk for $A D$ [20]. APOE $\varepsilon 4$ versus $\varepsilon 3$ children had a reduced $N A A / C r$ ratio in the right frontal white matter and decrements on attention, short-term memory, and below-average scores in Verbal and Full Scale IQ (>10 points). APOE modulated the group effects between WISC-R and left frontal and parietal white matter, and hippocampus metabolites. APOE $\varepsilon 4$ carriers could have a higher risk of developing early $A D$ if they reside in a polluted environment [19]. Higher concentrations of metals associated with PM: manganese $(p=0.003)$, nickel and chromium $(p=0.02)$ along with higher frontal COX2 mRNA and IL1 $\beta$ and olfactory bulb COX2-indicating neuroinflammation, are present in brains of Mexico City children and young adults, thus we also have to consider PM-metal neurotoxicity as a key factor likely accounting for brain damage in young urbanites[21]. 
Exposure to heavy metals including the emissions released by ferroalloy plants containing manganese and other metals are not uncommon, as shown in Valcamonica, Italy. High concentrations in soil and biomarkers associated with deficits in olfactory and motor function are the rule in children age 11-14 years [22].

In sharp contrast in terms of air pollutants, wood smoke exposures as measured by carbon monoxide yielded inverse associations between $\mathrm{CO}$ exposure of pregnant mothers during their 3rd trimesters and child neuropsychological performance, including deficits in visuo-spatial integration, short-term memory recall, long-term memory recall, and fine motor performance [15]. Longitudinal birth cohort studies on chronic early life pollutant exposures, bring up the issue of the critical importance of prenatal exposures and the role of the placental barrier in the final brain effects on the fetus. Curtis et al., identified glutamate as the active factor release from the placenta/cytotrophoblast barriers in vitro after hypoxia or hypoxia/reoxygenation, capable of damaging developing neurons under experimental conditions [23]. Thus, additional factors to consider would be the placental damage by the culprit air pollutant and the resulting release factors damaging the developing brain, functionally effective tight junctions present in embryonic brain, specific transport of plasma proteins across the blood-CSF barrier and embryo-specific intercellular junctions between neuroependymal cells lining the ventricles[24].

Polycyclic aromatic hydrocarbons (PAHs), the ubiquitous pollutants

PAHs exposures deserve special attention, because they are widely distributed in urban, occupational and rural environments and because in spite of their detrimental health and specific brain effects, we do not measure PAHs routinely. 
People's exposures to PAHs -complex mixtures containing over 100 compounds- are associated with fine particle bound PAHs, abounding in indoor and outdoor air, household environmental tobacco smoke, cooking with biomass, landfill biogases, petrochemical complex emissions, coke industry and steel metallurgy soil contamination, commuter life time in freeways and busy roadways, diets with smoked or charbroiled meat and meat products, frying oils and snacks, and occupational exposures. Marseille is a prime example of an urban port center with $>1$ million residents who - along residents in New York, Boston, Phoenix, Montreal, Los Angeles and Mexico City - are exposed to high concentrations of total PAHs (Figure 1A) and benzo [a]pyrene (Figure 1B).This stands in stark contrast to lower exposures in rural and suburban areas, i.e., Chesterfield, SC, population 5650, 30 people per $\mathrm{km}^{2}$ and Deer Park, TX, 3560 people per $\mathrm{km}^{2}$. The situation is worse in developing countries, where increases in migrant populations, poor atmospheric PAHs reduction measures from traffic and industry, and dependence on biofuel contribute to high levels of PAH and $\mathrm{PM}_{2.5}$ as is the case of Metropolitan Mexico City where 24 million residents are greatly exposed on daily bases (Figures 1A, 1B).
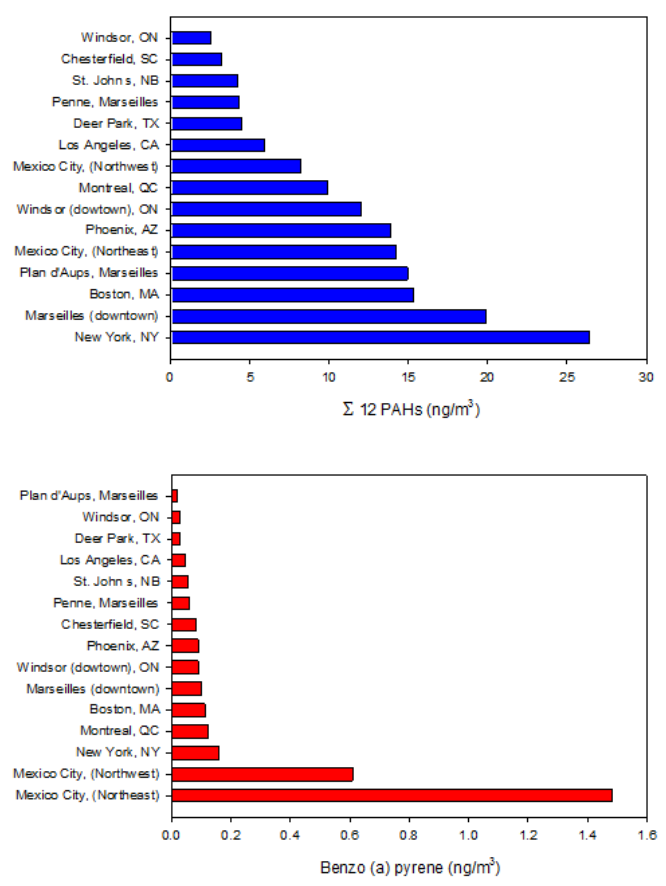

Figure 1. (A) Sum of the average concentrations of $12 \mathrm{PAHs}$, and, (B) the average concentrations of Benzo(a)pyrene in PM in several areas of North America and South of France. 
The sum of the PAHs include: phenanthrene, benzo(a)pyrene, benzo(b)fluoranthene, benzo(a)anthracene, fluorene, fluoranthene, pyrene, chrysene, benzo(k)fluoranthene, dibenzo(a,h)anthracene, indene(1,2,3-cd)pyrene, and Benzo(ghi)perylene. Data of PAHs are for the years: 2012 Canada sites; 2010 U.S.A. sites, 2005-2007 Mexico City sites, and July, 2004 South of France.

Prenatal PAHs exposures are harmful to the developing brain, high levels of PAH-DNA adducts in cord blood have been associated with neural tube defects, and occupational exposures during pregnancy increase the risk for small for gestational age babies [25-27]. In the U.S. exposures to PAHs as measured by urine metabolites, are seen across all ages with particularly high concentrations in 6 to 11 year olds [28]. Heating oil combustion and indoor sources of pyrene are key contributors to PAHs in cities like New York [29]. PAHs exposures are also associated with higher body mass index (BMI), waist circumference and obesity in 6-11 year old U.S. children [30]. Readers also have to be aware that high levels of poverty, low educational attainment, and below average mother's IQ are critical confounder factors to evaluate cognition in children exposed to air pollutants [25].

\section{Neuroinflammatory and neurodegenerative changes}

In the common scenario of air pollution exposures, i.e., the urban resident living close to a busy road, exposed to complex mixtures in his way to work, driving his car, taking the bus or the subway, with a work place with other sources of toxics, goes back to his home where cooking is taking place, has a cigarette before going to bed, puts the heat on or opens the windows for ventilation, etc., inflammation is the key pathway linking complex pollutant exposures and CNS damage. 
The initial inflammatory process involves the upper and lower respiratory tract, follow by spilling of the process to a systemic inflammatory response and the production of inflammatory mediators capable of reaching the brain. If our lady urbanite is pregnant, then air pollutant components can cross the placental barrier, directly affecting the embryo and the fetus [23, 24]. Continuous expression of potent inflammatory mediators in the CNS and the formation of reactive oxygen species (ROS) are major findings in urban residents. Ultrafine PM (UFPM), PM-LPS, and metal uptake take place through olfactory neurons, cranial nerves such as the trigeminal and vagus, the GI tract, the systemic circulation, and macrophage-like cells loaded with PM from the lungs[31-36]. Swallowing of tiny particles for example, allows for the direct contact of particulate components with the fragile small bowel mucosa, disrupting the tight junctions and breaking the integrity of the gastrointestinal (GI) barrier [36]. Activation of the brain innate immune responses resulting from the interaction between circulating cytokines and constitutively expressed cytokine receptors located in brain endothelial cells is followed by activation of cells involved in adaptive immunity[37]. Interactions between microglia, mast cells, endothelial cells, and macrophages are critical in inflammation and impact behavior [38, 39].

Systemic oxidative stress and brisk inflammatory responses are seen in animal models and in humans exposed to polluted environments with diverse PM chemistry, including residual oil flash, endotoxins, and metals as well as high concentrations of criteria pollutants[40-42]. The individual inflammatory responses to air pollutants depend of diverse factors, including mitochondrial genetic background, age, gender, and chronic diseases [43, 44].

A key component of air pollution exposure is neuroinflammation [45]. In megacity children there is a significant frontal lobe imbalance in genes essential for inflammation, innate and adaptive immune responses, oxidative stress, cell proliferation and apoptosis [33]. The up-regulation of potent inflammatory mediators involves supra and infratentorial regions and cranial nerves including: olfactory bulb, frontal cortex, substantia nigrae and the vagus [35]. 
Chronic inflammatory perivascular infiltrates and activated microglia in the frontal and temporal cortex, subicular area, and the brainstem are commonly present in MCMA children, while they are rare in controls. There is also evidence of highly oxidized and covalently cross-linked aggregates of proteins affecting endothelial cells in brain capillaries i.e., the presence of abundant lipofuscin [35]. This finding is good evidence of a dysfunctional lysosomal degradation, not expected in children or young adults.

Based on the current literature, we know that air pollution PM and environmental nanoparticles are risk factors for the development of neuroinflammation and neurodegeneration[46-51]. Ultrafine particles (UFPs) are the most abundant particulate pollutants in urban and industrial areas, and their exposures have increased significantly because of anthropogenic sources including internal combustion engines, power plants, incinerators and many other sources of thermo-degradation. UFPs are able to stimulate inflammatory responses, damaging epithelial cells, breaking barriers and gaining access to the interstitium[46]. There are a significant number of proteins adsorbed onto 20 $\mathrm{nm}$ sized $\mathrm{SiO} 2$ nanoparticles than onto the $100 \mathrm{~nm}$ sized nanoparticles regardless of charge. Proteins bound on the surface of nanoparticles may affect functional and conformational properties and distributions in complicated biological brain processes[51]. Exposure to different size and composition PM is associated with production and deposit of misfolded protein aggregates (amyloid, alpha synuclein, hyperphosphorilated tau), oxidative stress, cell damage and death in susceptible neuronal populations [52-54].

The early neural events including extensive oxidative stress [55], observed in our exposed populations are key for pathways conducing to neurodegeneration, since recent works emphasize AD pathology as "an active host response or an environmental adaptation" [56]. 
The presence of neuroinflammation as evidenced by up-regulation of gene network clusters interleukin-1 (IL-1), nuclear factor kappa B (NFKB), interferon (IFN) and toll-like receptors (TLRs) along with tau hyperphosphorilation in MCMA children and young adults compared to controls, supports the role of air pollution in their brain responses [33]. A 15-fold frontal lobe downregulation of the prion-related protein $(\operatorname{PrP}(C))$ was a striking finding in MCMA young urbanites[33]. The down-regulation of the $\operatorname{PrP}(\mathrm{C})$ is critical given its important roles for neuroprotection, neurodegeneration, and mood disorder states.

\section{Breakdown of epithelial and endothelial barriers: no barrier is intact.}

All barriers are damaged by air pollutants. A common target and a portal of entry are the nasal passages. A key feature of a chronically inflamed nasal and paranasal epithelia is that inflammatory mediators are released to the systemic circulation[57], and thus, their contribution to systemic inflammation and dysregulation are important. The issue acquires a great importance in the context of air pollution because olfactory dysfunction is among the earliest features of AD and Parkinson's disease (PD), occurring in 90\% of early onset cases [58]. Early olfactory deficits in MCMA young residents appear to be associated with the presence of $\beta$ amyloid, $\alpha$ synuclein, ultrafine PM $(<100 \mathrm{~nm})$ in glomerular structures and massive distortion of the olfactory bulb organization[34].

While the breakdown of the nasal, olfactory, BBB, and alveolar-capillary barriers has been extensively documented, the research on the involvement of the gastrointestinal barrier is at the earliest stages. There is evidence the GI tract barrier is also compromised in the air pollution setting and recent research links inflammatory bowel diseases, changes in gut microbiome, and abdominal pain with air pollution [59-62]. The integrity of the gastrointestinal (GI) barrier is compromised in $M C$ dogs and could be altered in $M C$ children as evidenced by the autoimmune response to $\mathrm{TJ}$ and neural proteins $[31,36]$. 
The GI breakdown likely impacts neuronal enteric populations and PM could reach the vagus and the brainstem. In the setting of urban air pollution, the evolution of a changing paradigm favoring a pathogen penetrating an epithelial lining and via transsynaptic transmission reaching preganglionic parasympathetic motor neurons of the vagus nerve[63] has to entertain environmental swallowed particulate matter as a potential culprit. We suggested that damage to epithelial and endothelial barriers associated to air pollution exposures is a robust trigger of tight junction and neural antibodies [31]. Cryptic 'self' tight junction antigens can trigger an autoimmune response potentially contributing to the neuroinflammatory and Alzheimer and Parkinson's pathology present in megacity children. A key piece of information is that a major factor determining the impact of neural autoantibodies is the integrity of the blood-brain barrier[64, 65]. Thus immunological dysregulation and the critical "double-edged sword" [56] of a fine balance between protective and detrimental effects as a response to air pollution in a developing brain is a major issue in young urbanites [37].

\section{Brainstem pathology}

Brainstem neuroinflammatory and degenerative changes are key in exposed children and young adults. Misfolded $\alpha$-synuclein is present in $23.5 \%$ of $<25$ y MC residents [66] and the brainstem distribution of this protein follows key anatomical regions known to be involved early in Parkinson's disease (PD) stages [67, 68]. Specifically, $\alpha$-synuclein has been observed in the dorsal vagal nucleus, solitary complex, lower raphe nuclei, locus coeruleus and pedunculo-pontine nuclei, as well as in the olfactory bulb of young MC residents [34,66]. These findings correspond to Braak stages I and II of PD characterized by autonomic and olfactory disturbances[67-69], that are indeed present in our exposed pediatric cohorts [66]. Our observations put forward a key question raised by numerous researchers: What events trigger the onset of Parkinson's disease? One important question begging an answer because by the time PD motor symptoms are present, the pathology is irreversible[70]. 
If we follow Braak's PD neuropathology staging, the earlier pathological changes (stages I and II) are observed in the olfactory bulb and brainstem; the motor symptoms relate to stage III and beyond. Further, autonomic disturbances are early, as many as 4 decades before motor manifestations. It would be extremely difficult to ignore landmark papers pointing towards the relationship between the intranasal neurotoxicant and biologically plausible pathways in explaining involvement of key early PD targets, namely the mucosal barrier of the gastrointestinal tract and, via postganglionic enteric neurons, entering the central nervous system along unmyelinated praganglionic fibers generated from the visceromotor projection cells of the vagus nerve" [63], and the olfactory vector hypothesis[71]. We propose these potential pathways are involved in highly exposed urban children and more importantly, that they lead to involvement of the brainstem.

\section{Alzheimer's and Parkinson's diseases and air pollution}

The interpretation of the early oxidative stress, the upregulation of key gene pathways, neuroinflammation, misfolded proteins in key anatomical areas, etc., in the brains of children and young adults with lifetime high exposures to air pollutants is critical to the origin of neurodegeneration in $\mathrm{AD}$ and $\mathrm{PD}$. As Castellani and Perry[56] point it out, the prevailing paradigm of neurodegenerative changes being the etiology rather than a response to detrimental environments at different levels, no longer holds. We are showing early AD and PD hallmarks in MCMA children and our findings are not isolated given that other authors are showing that the development of abnormal tau for example, starts in childhood [72, 73]. Critical to our human studies, systemic inflammation, neuroinflammation and misfolded protein aggregates are progressive features elicited upon the administration of air pollutant components to experimental animals[52-54, 74-76]. Our interpretation of AD and PD hallmarks in the setting of air pollution is on the side of initial protective responses $[32,33]$. In the Alzheimer's brain, tau is abnormally hyperphosphorylated (HP) [77]. 
Tau phosphorylation could be protective (e.g., hibernation) or toxic (e.g., hyperphosphorylation and aggregation of tau)[78]. Although the aggregation of HP tau species has been proposed to represent a compensatory neuronal response against oxidative stress and to serve at least initially as a protector against cell death[79, 80], the detrimental effects of abnormal tau in $\mathrm{AD}$, related tautopathies and under experimental conditions are not subject to controversy $[55,78,81-84]$. Jung et al., work establishes the strong association between long-term exposure to $\mathrm{O}_{3}$ and $\mathrm{PM}_{2.5}$ above the current US EPA standards and increased Alzheimer's disease risk in a cohort of individual $>65 \mathrm{y}$. They found a $138 \%$ risk of increase of AD per increase of $4.34 \mu \mathrm{g} / \mathrm{m} 3$ in PM2.5 over the 10y follow-up period [85]. Jung's work is very relevant to our work and brings the issue of Alzheimer's disease development over several decades and thus is subject to neuroprotective interventions.

If cellular defense mechanisms try to intervene but fail, as strongly suggested by several authors [86], and gene studies point towards the strong association with networks characterized by the very same common denominators i.e., oxidative stress, seen in common diseases that are causing high morbility and mortality (cancer, diabetes, renal diseases, and cardiovascular diseases), then why not pursue the notion that gene changes and the pathology in urban children is indicative of an active host response or environmental adaptation as suggested by Castellani and Perry [56].

Alpha-synuclein aggregation is associated to the pathogenesis of Parkinson's disease and exposure to a myriad of environmental agents, including agrochemicals increases PD risk[87, 88]. That being said, we need to emphasize that $\alpha$-synuclein in MC children is present in key regions associated with PD pathology: olfactory bulb, midbrain and the lower sections of the brainstem, e.g., the medulla oblongata. Moreover, MC teens exhibit already olfactory disturbances and autonomic dysfunction (i.e., syncope) severe enough to require pediatric care. 
The presence of up-regulated inflammatory cytokines, $\alpha$-synuclein and HP $\pi$ olfactory bulb pathology in MCMA children along the breakdown of the GI duodenal barrier in Mexico City young dogs and autoantibodies against tight junction proteins, are ominous signs possibly associated with a number of other non-motor symptoms related to PD, such as dysautonomia and sleep disturbances[89, 90].

The key role of APOE 4

The results of the clinical and neuropathological studies in highly exposed children strongly suggests that carriers of the allele $\varepsilon 4$ of apolipoprotein $\mathrm{E} 4(A P O E \varepsilon 4)$, the most prevalent genetic risk factor for sporadic $\mathrm{AD}(21)$, have significantly more cognitive and neuropathology changes that $A P O E \& 3$ carriers.

If indeed there is interest in preventing $\mathrm{AD}$, if we know that urban children with an $A P O E \varepsilon 4$ are clearly showing cognitive deficits, greater hyperphosphorylated tau and diffuse $\mathrm{A} \beta$ plaques versus E3 carriers $(\mathrm{Q}=7.82, \mathrm{p}=0.005)$ [37] why not to target apoE4 and pave the way for future studies? Pediatric research linking Alzheimer's early hallmarks with air pollution has been totally ignored by the grant supporting institutions.

\section{The need for neuroprotection in high-risk children and young adults}

Early neuroprotection of high-risk urban children and young adults should be in the agenda of health federal agencies. The inducible regulation of key gene pathways in young brains suggests they are evolving different mechanisms in an attempt to cope with the constant state of inflammation and oxidative stress related to their environmental exposures[33]. Cellular defense mechanisms try to intervene but fail, finally resulting in AD pathology as the disease progresses[91]. Oxidative stress is at the core of Alzheimer's disease and genomic vulnerability [92] is important in the scenario of air pollution. 


\section{Environmental risk factors in MS}

Many factors, including both genetic and environmental, have been suspected of being associated with MS. A complex interaction between environmental factors with susceptibility genes probably leads to the onset of the disease. The most likely environmental factors are sunlight exposure mediating vitamin D synthesis and UV radiation [93]. EBV stands out as an infectious agent that can explain many features of MS epidemiology[94]. Several lines of evidence also suggest smoking as a modifiable risk factor for MS [95-97].

\subsection{Air pollution as a risk factor in MS}

UV and vitamin D have been implied as most prominent environmental factors describing the latitudinal gradient of MS prevalence observed among European descent nations [98]. There is an inverse relationship between serum vitamin D level and MS clinical activity [99]. High circulating levels of vitamin D are associated with a lower risk of multiple sclerosis [100, 101]. Exposure to sunlight is the main source of vitamin D requirement for many people and may also exert a protective effect in MS patients.

Air pollutants could also contribute to low circulating vitamin D levels of inhabitants of polluted areas. Women and children in areas with high levels of air pollutants had significantly lower vitamin D level $[102,103]$. Increased maternal exposure to NO2 and PM10 during the whole pregnancy might be associated to lower cord blood serum 25(OH) D levels at birth [104], furthermore the high tropospheric ozone content of urban areas is also a risk factor for vitamin D deficiency [105]. 
Adverse effects of air pollutants on central nervous system has been observed in post-mortem studies of inhabitants of polluted cities [106]. In a later study, neuroinflammation, altered blood brain barrier, and particulate deposition in the brain of children and young adults living in cities with high air pollution was observed [35]. Only few studies have considered possible role of air pollutants in pathogenesis of MS or of MS relapses. They are described below.

A retrospective study in south-western Finland, including 1205 relapses which occurred among 406 patients in 14-year period 1985-1999, has shown a strong relationship between MS relapses and peak amounts in PM10 and $\mathrm{SO}_{2}+\mathrm{NO}_{2}+\mathrm{NO}$ levels [107]. Odds ratio were respectively 3.0 [1.27.7] and 11.7 [3.3-42.0] without lag, and 4.1 [1.6-10.6] and 9.3 [2.7-31.4] with one month lag. This study was conducted on a long period and included a large number of events that were systematically authenticated by a neurologist. However, no information regarding DMTs or clinical characteristics of the disease was considered, and the methods to measure air pollutants were not described. Therefore, the exposure measurements may be not so accurate.

The best model predicting clustered pattern of female MS patients in Georgia included PM10 [108]. This American study has studied MS prevalence at county level in Georgia using an ecological design. Significant associations were found between MS prevalence and PM10 levels, as well as MS prevalence and income levels. Study population comprised 9072576 people, of whom 6247 were declared as MS to the regional section of «Multiple Sclerosis Society ». This study, despite its large size, has several methodological weaknesses, such as self-declared diagnosis of MS (not validated by neurologists), lack of ageadjusted prevalence estimates, and imprecise measure of air pollutants (county level which is big). Moreover, there may be a potential bias in the chronological sequence between exposure measured in 1999 and MS prevalence measured in 2005. 
Indeed, MS cases who started before 1999 are included while they have not been exposed to the studied exposure, unless pollution levels in 1999 are supposed to be equivalent to previous levels.

Clustering pattern of MS prevalence patients were also observed in Tehran [109, 110], and a significant difference in long term exposure to $\mathrm{PM}_{10}, \mathrm{SO}_{2}, \mathrm{NO}_{2}$, and $\mathrm{NO}_{\mathrm{x}}$ was observed in MS cases compared with controls [109]. A recent study in Tehran found higher relapse rate during the winter and following first month of the spring and MS relapses were correlated with NO levels [111]. They also found that most air pollutants such as $\mathrm{NO} 2, \mathrm{NO}$ and $\mathrm{CO}$ are in high levels in the rainy season. Others like Pm10 and Nox are in high levels in the dry season. The correlation between NO2 levels of all markers of air quality and MS relapses $(P=0.03, \mathrm{r}=0.27)$ was weak. Best ARIMA model was determined between number of monthly relapses and living place, although this model was not significant $(P=0.3)$.

In Serbia, the results confirmed the influence of air pollution and climate seasonal conditions on disease relapses in MS patients based on a long-term observation (5 years). Lower numbers of days with low air pollution during the periods with low vitamin D (January-April), especially with increased cloudiness at 2 p.m, induce a higher risk of MS relapses in southern continental parts of Europe [112] . In this study, period under DMTs were excluded, and the diagnosis of relapses were always established by MS specialized neurologists. Methods to measure exposure are clearly exposed. Oikonen et al suggested that $\mathrm{PM}_{10}$ increased susceptibility to adenoviral infections, hence increasing the relapse rate in MS patients [113].

A French study regarding the potential association between air pollutants and MS relapses is ongoing in Strasbourg city in North Eastern France. A total of 254 patients accounting for 1143 relapses in the period 2000-2009 have been included. A case crossover design has been selected, i.e. the analysis will be performed by comparing among each patient the air pollutants levels observed in period where relapses occurred with period without relapses. 
This design allows controlling for individual confusion factors such as gender, age at MS onset etc.

Preliminary results (unpublished yet) showed a significant association between PM10 levels during the 3 previous days and the risk of relapse $(\mathrm{OR}=1.3 ; 95 \% \mathrm{Cl} 1.1-1.7)$

Seasonal variation of MS relapses was also confirmed in a recent metaanalysis. Their frequency is higher in spring and lower in winter, which is in favor of seasonal risk factors for MS, such as air pollutants.

\subsection{Air pollutants play a role in neuroinflammation}

Evidence from lab studies suggest that ultrafine particulate matter affects CNS inflammatory processes and increase biomarkers of inflammation in mouse brain $[114,115]$. Levels of proinflammatory cytokines (IL-1 $\alpha$, TNF- $\alpha$ ) and the immune related transcription factor (NF-kB) were increased in brain tissue of mice exposed to particulate matter compared to that of control animals [114]. Mice exposed to two levels of concentrated ultrafine particulate matter in central Los Angeles showed aberrant immune activation in the brains as judged by a dose-related increase in nuclear translocation of two key inflammatory transcription factors (NF-KB and AP-1)[115]. In another study, baseline levels of the pro-inflammatory cytokines (TNF- $\alpha$, IL-1 $\alpha$ ) were increased in the striatum after exposure to diesel engine exhaust. A similar, though not significant, trend was seen with the mRNA expression levels of TNF- $\alpha$ and TNF Receptor-subtype I [116].

\section{Future directions}

Variations in exposure to air pollutants during disease course should be quantified in longitudinal studies with detailed assessment batteries on various clinical aspects of MS to allow researchers reveal potential role of air pollutants in MS pathogenesis. Appropriate study designs have to be selected in order to control to most of confounding and reach a high level of evidence. Moreover, epigenetic studies may be of interest in order to highlight the mechanisms responsible for the role of air pollutants in pathogenesis of MS or MS relapses. 


\section{Conclusions}

Air pollution has become a key issue in Public Health (at a local and regional level) and in Environmental Sciences. What can we do? Improving air quality and identifying the young urbanites with the most risk for neurodegeneration are key to protect our residents. But solutions will have to come from Policy and politics.

Early cognitive deficits are associated with prenatal and early postnatal air pollutant exposures, brain structural, volumetric and metabolic changes are described in adolescence and early adulthood with significant cognitive deficits that will negatively impact the academic, labour and social performance of the affected individuals. Pursuing the notion that gene pathway changes and the neuropathology in urban children and young adults is indicative of an active host response or environmental adaptation [56] and that genetic factors play a key role ( $A P O E \varepsilon 4)(21)$ why not target the obvious and pave the way for future studies?

It is interesting to consider the evolution of the awareness of this issue. Disasters related to acute air pollution hit Europe and the US in the twenty-century. They led to a great societal and political concern and to regulatory actions (Clean Air Act in 1956 UK and in 1970 in the US) [2], extending progressively into the word (e.g. European Clean Air Package)[117]. By the end of the twenty-century, air quality improves in western countries: lower pollutants concentration, mostly chronic or sub-acute exposure. 


\section{References}

1. Reis J, Roman GC. Environmental neurology: a promising new field of practice and research. Journal of the neurological sciences. 2007;262(1-2):3-6.

2. Zhang JJ, Samet JM. Chinese haze versus Western smog: lessons learned. Journal of thoracic disease. 2015;7(1):3-13.

3. Kyle AD, Wright CC, Caldwell JC, Buffler PA, Woodruff TJ. Evaluating the health significance of hazardous air pollutants using monitoring data. Public health reports. 2001;116(1):32-44.

4. Bakian AV, Huber RS, Coon H, Gray D, Wilson P, McMahon WM, et al. Acute air pollution exposure and risk of suicide completion. American journal of epidemiology. 2015;181(5):295-303.

5. Stafoggia M, Cesaroni G, Peters A, Andersen ZJ, Badaloni C, Beelen R, et al. Long-term exposure to ambient air pollution and incidence of cerebrovascular events: results from 11 European cohorts within the ESCAPE project. Environmental health perspectives. 2014;122(9):919-25.

6. Fecht D, Fischer P, Fortunato L, Hoek G, de Hoogh K, Marra M, et al. Associations between air pollution and socioeconomic characteristics, ethnicity and age profile of neighbourhoods in England and the Netherlands. Environmental pollution. 2015;198:201-10.

7. Platt SM, Haddad IE, Pieber SM, Huang RJ, Zardini AA, Clairotte M, et al. Two-stroke scooters are a dominant source of air pollution in many cities. Nature communications. 2014;5:3749.

8. Suissa L, Fortier M, Lachaud S, Staccini P, Mahagne MH. Ozone air pollution and ischaemic stroke occurrence: a case-crossover study in Nice, France. BMJ open. 2013;3(12):e004060.

9. Calderon-Garciduenas L, Mora-Tiscareno A, Ontiveros E, Gomez-Garza G, Barragan-Mejia G, Broadway J, et al. Air pollution, cognitive deficits and brain abnormalities: a pilot study with children and dogs. Brain and cognition. 2008;68(2):117-27.

10. Calderon-Garciduenas L, Mora-Tiscareno A, Styner M, Gomez-Garza G, Zhu H, Torres-Jardon R, et al. White matter hyperintensities, systemic inflammation, brain growth, and cognitive functions in children exposed to air pollution. Journal of Alzheimer's disease : JAD. 2012;31(1):183-91.

11. Calderon-Garciduenas L, Engle R, Mora-Tiscareno A, Styner M, Gomez-Garza G, Zhu H, et al. Exposure to severe urban air pollution influences cognitive outcomes, brain volume and systemic inflammation in clinically healthy children. Brain and cognition. 2011;77(3):345-55.

12. Yolton K, Dietrich K, Auinger P, Lanphear BP, Hornung R. Exposure to environmental tobacco smoke and cognitive abilities among U.S. children and adolescents. Environmental health perspectives. 2005;113(1):98-103.

13. Suglia SF, Gryparis A, Wright RO, Schwartz J, Wright RJ. Association of black carbon with cognition among children in a prospective birth cohort study. American journal of epidemiology. 2008;167(3):280-6.

14. van Kempen E, Fischer P, Janssen N, Houthuijs D, van Kamp I, Stansfeld S, et al. Neurobehavioral effects of exposure to traffic-related air pollution and transportation noise in primary schoolchildren. Environmental research. 2012;115:18-25.

15. Dix-Cooper L, Eskenazi B, Romero C, Balmes J, Smith KR. Neurodevelopmental performance among school age children in rural Guatemala is associated with prenatal and postnatal exposure to carbon monoxide, a marker for exposure to woodsmoke. Neurotoxicology. 2012;33(2):246-54.

16. Kim E, Park H, Hong YC, Ha M, Kim Y, Kim BN, et al. Prenatal exposure to PM(1)(0) and NO(2) and children's neurodevelopment from birth to 24 months of age: mothers and Children's Environmental Health (MOCEH) study. The Science of the total environment. 2014;481:439-45.

17. Kicinski M, Vermeir G, Van Larebeke N, Den Hond E, Schoeters G, Bruckers L, et al. Neurobehavioral performance in adolescents is inversely associated with traffic exposure. Environment international. 2015;75:136-43.

18. Murray AD, McNeil CJ, Salarirad S, Whalley LJ, Staff RT. Early life socioeconomic circumstance and late life brain hyperintensities--a population based cohort study. PloS one. 2014;9(2):e88969.

19. Calderon-Garciduenas L, Mora-Tiscareno A, Franco-Lira M, Zhu H, Lu Z, Solorio E, et al. Decreases in Short Term Memory, IQ, and Altered Brain Metabolic Ratios in Urban Apolipoprotein epsilon4 Children Exposed to Air Pollution. Journal of Alzheimer's disease : JAD. 2015;45(3):757-70. 
Alzheimer's disease. Alzheimer's \& dementia : the journal of the Alzheimer's Association. 2014;10(6):861-8.

21. Calderon-Garciduenas L, Serrano-Sierra A, Torres-Jardon R, Zhu H, Yuan Y, Smith D, et al. The impact of environmental metals in young urbanites' brains. Experimental and toxicologic pathology : official journal of the Gesellschaft fur Toxikologische Pathologie. 2013;65(5):503-11.

22. Lucchini RG, Guazzetti S, Zoni S, Donna F, Peter S, Zacco A, et al. Tremor, olfactory and motor changes in Italian adolescents exposed to historical ferro-manganese emission. Neurotoxicology. 2012;33(4):687-96.

23. Curtis DJ, Sood A, Phillips TJ, Leinster VH, Nishiguchi A, Coyle C, et al. Secretions from placenta, after hypoxia/reoxygenation, can damage developing neurones of brain under experimental conditions. Experimental neurology. 2014;261:386-95.

24. Saunders NR, Liddelow SA, Dziegielewska KM. Barrier mechanisms in the developing brain. Frontiers in pharmacology. 2012;3:46.

25. Peterson BS, Rauh VA, Bansal R, Hao X, Toth Z, Nati G, et al. Effects of Prenatal Exposure to Air Pollutants (Polycyclic Aromatic Hydrocarbons) on the Development of Brain White Matter, Cognition, and Behavior in Later Childhood. JAMA psychiatry. 2015.

26. Yi D, Yuan Y, Jin L, Zhou G, Zhu H, Finnell RH, et al. Levels of PAH-DNA adducts in cord blood and cord tissue and the risk of fetal neural tube defects in a Chinese population. Neurotoxicology. 2015;46:73-8.

$27 . \quad$ Langlois PH, Hoyt AT, Desrosiers TA, Lupo PJ, Lawson CC, Waters MA, et al. Maternal occupational exposure to polycyclic aromatic hydrocarbons and small for gestational age offspring. Occupational and environmental medicine. 2014;71(8):529-35.

28. Li Z, Sandau CD, Romanoff LC, Caudill SP, Sjodin A, Needham LL, et al. Concentration and profile of 22 urinary polycyclic aromatic hydrocarbon metabolites in the US population. Environmental research. 2008;107(3):320-31.

29. Jung KH, Liu B, Lovinsky-Desir S, Yan B, Camann D, Sjodin A, et al. Time trends of polycyclic aromatic hydrocarbon exposure in New York City from 2001 to 2012: assessed by repeat air and urine samples. Environmental research. 2014;131:95-103.

30. Scinicariello F, Buser MC. Urinary polycyclic aromatic hydrocarbons and childhood obesity: NHANES (2001-2006). Environmental health perspectives. 2014;122(3):299-303.

31. Calderon-Garciduenas L, Vojdani A, Blaurock-Busch E, Busch Y, Friedle A, Franco-Lira M, et al. Air pollution and children: neural and tight junction antibodies and combustion metals, the role of barrier breakdown and brain immunity in neurodegeneration. Journal of Alzheimer's disease : JAD. 2015;43(3):1039-58.

32. Calderon-Garciduenas L, Franco-Lira M, Mora-Tiscareno A, Medina-Cortina H, Torres-Jardon R, Kavanaugh M. Early Alzheimer's and Parkinson's disease pathology in urban children: Friend versus Foe responses--it is time to face the evidence. BioMed research international. 2013;2013:161687.

33. Calderon-Garciduenas L, Kavanaugh M, Block M, D'Angiulli A, Delgado-Chavez R, Torres-Jardon $R$, et al. Neuroinflammation, hyperphosphorylated tau, diffuse amyloid plaques, and down-regulation of the cellular prion protein in air pollution exposed children and young adults. Journal of Alzheimer's disease : JAD. 2012;28(1):93-107.

34. Calderon-Garciduenas L, Franco-Lira M, Henriquez-Roldan C, Osnaya N, Gonzalez-Maciel A, Reynoso-Robles R, et al. Urban air pollution: influences on olfactory function and pathology in exposed children and young adults. Experimental and toxicologic pathology : official journal of the Gesellschaft fur Toxikologische Pathologie. 2010;62(1):91-102.

35. Calderon-Garciduenas L, Solt AC, Henriquez-Roldan C, Torres-Jardon R, Nuse B, Herritt L, et al. Long-term air pollution exposure is associated with neuroinflammation, an altered innate immune response, disruption of the blood-brain barrier, ultrafine particulate deposition, and accumulation of amyloid beta-42 and alpha-synuclein in children and young adults. Toxicologic pathology. 2008;36(2):289310.

36. Calderón-Garcidueñas Lilian G-MA, Vojdani Aristo, Franco-Lira Maricela, Reynoso-Robles Rafael, Montesinos-Correa Hortencia, Pérez-Guillé Beatriz , Sarathi Mukherjee Partha ,Torres-Jardón Ricardo , Calderón-Garcidueñas Ana , Perry George. The Intestinal Barrier in Air Pollution-Associated Neural Invol vement in Mexico City Residents: Mind the Gut, the Evolution of a Chan ging Paradigm Relevant to 
Parkinson Disease Risk. Journal of Alzheimers Disease \& Parkinsonism. 2015;5(1):1-12.

37. Lampron A, Elali A, Rivest S. Innate immunity in the CNS: redefining the relationship between the CNS and Its environment. Neuron. 2013;78(2):214-32.

38. Wohleb ES, McKim DB, Sheridan JF, Godbout JP. Monocyte trafficking to the brain with stress and inflammation: a novel axis of immune-to-brain communication that influences mood and behavior. Frontiers in neuroscience. 2014;8:447.

39. Dong H, Zhang X, Qian Y. Mast cells and neuroinflammation. Medical science monitor basic research. 2014;20:200-6.

40. Huang W, Wang G, Lu SE, Kipen H, Wang Y, Hu M, et al. Inflammatory and oxidative stress responses of healthy young adults to changes in air quality during the Beijing Olympics. American journal of respiratory and critical care medicine. 2012;186(11):1150-9.

41. Behbod B, Urch B, Speck M, Scott JA, Liu L, Poon R, et al. Endotoxin in concentrated coarse and fine ambient particles induces acute systemic inflammation in controlled human exposures. Occupational and environmental medicine. 2013;70(11):761-7.

42. Marchini T, Magnani ND, Paz ML, Vanasco V, Tasat D, Gonzalez Maglio DH, et al. Time course of systemic oxidative stress and inflammatory response induced by an acute exposure to Residual Oil Fly Ash. Toxicology and applied pharmacology. 2014;274(2):274-82.

43. Wittkopp S, Staimer N, Tjoa T, Gillen D, Daher N, Shafer M, et al. Mitochondrial genetic background modifies the relationship between traffic-related air pollution exposure and systemic biomarkers of inflammation. PloS one. 2013;8(5):e64444.

44. Huttunen K, Siponen T, Salonen I, Yli-Tuomi T, Aurela M, Dufva H, et al. Low-level exposure to ambient particulate matter is associated with systemic inflammation in ischemic heart disease patients. Environmental research. 2012;116:44-51.

45. Block ML, Calderon-Garciduenas L. Air pollution: mechanisms of neuroinflammation and CNS disease. Trends in neurosciences. 2009;32(9):506-16.

46. Terzano C, Di Stefano F, Conti V, Graziani E, Petroianni A. Air pollution ultrafine particles: toxicity beyond the lung. European review for medical and pharmacological sciences. 2010;14(10):809-21.

47. Wu J, Wang C, Sun J, Xue Y. Neurotoxicity of silica nanoparticles: brain localization and dopaminergic neurons damage pathways. ACS nano. 2011;5(6):4476-89.

48. Win-Shwe TT, Fujimaki H. Nanoparticles and neurotoxicity. International journal of molecular sciences. 2011;12(9):6267-80.

49. Sharma HS, Sharma A. Neurotoxicity of engineered nanoparticles from metals. CNS \& neurological disorders drug targets. 2012;11(1):65-80.

50. Sharma A, Muresanu DF, Patnaik R, Sharma HS. Size- and age-dependent neurotoxicity of engineered metal nanoparticles in rats. Molecular neurobiology. 2013;48(2):386-96.

51. Shim KH, Hulme J, Maeng EH, Kim MK, An SS. Analysis of SiO2 nanoparticles binding proteins in rat blood and brain homogenate. International journal of nanomedicine. 2014;9 Suppl 2:207-15.

52. Levesque S, Taetzsch T, Lull ME, Kodavanti U, Stadler K, Wagner A, et al. Diesel exhaust activates and primes microglia: air pollution, neuroinflammation, and regulation of dopaminergic neurotoxicity. Environmental health perspectives. 2011;119(8):1149-55.

53. Levesque S, Taetzsch T, Lull ME, Johnson JA, McGraw C, Block ML. The role of MAC1 in diesel exhaust particle-induced microglial activation and loss of dopaminergic neuron function. Journal of neurochemistry. 2013;125(5):756-65.

54. Levesque S, Surace MJ, McDonald J, Block ML. Air pollution \& the brain: Subchronic diesel exhaust exposure causes neuroinflammation and elevates early markers of neurodegenerative disease. Journal of neuroinflammation. 2011;8:105.

55. Wang X, Wang W, Li L, Perry G, Lee HG, Zhu X. Oxidative stress and mitochondrial dysfunction in Alzheimer's disease. Biochimica et biophysica acta. 2014;1842(8):1240-7.

56. Castellani RJ, Perry G. The complexities of the pathology-pathogenesis relationship in Alzheimer disease. Biochemical pharmacology. 2014;88(4):671-6.

57. Calderon-Garciduenas L, Macias-Parra M, Hoffmann HJ, Valencia-Salazar G, Henriquez-Roldan C, Osnaya $\mathrm{N}$, et al. Immunotoxicity and environment: immunodysregulation and systemic inflammation in children. Toxicologic pathology. 2009;37(2):161-9.

58. Doty RL. Olfaction in Parkinson's disease and related disorders. Neurobiology of disease. 
2012;46(3):527-52.

59. Bergin IL, Witzmann FA. Nanoparticle toxicity by the gastrointestinal route: evidence and knowledge gaps. International journal of biomedical nanoscience and nanotechnology. 2013;3(1-2).

60. Kaplan GG, Szyszkowicz M, Fichna J, Rowe BH, Porada E, Vincent R, et al. Non-specific abdominal pain and air pollution: a novel association. PloS one. 2012;7(10):e47669.

61. Kaplan GG, Hubbard J, Korzenik J, Sands BE, Panaccione R, Ghosh S, et al. The inflammatory bowel diseases and ambient air pollution: a novel association. The American journal of gastroenterology. 2010;105(11):2412-9.

62. Kish L, Hotte N, Kaplan GG, Vincent R, Tso R, Ganzle M, et al. Environmental particulate matter induces murine intestinal inflammatory responses and alters the gut microbiome. PloS one.

2013;8(4):e62220.

63. Braak H, Rub U, Gai WP, Del Tredici K. Idiopathic Parkinson's disease: possible routes by which vulnerable neuronal types may be subject to neuroinvasion by an unknown pathogen. Journal of neural transmission (Vienna, Austria : 1996). 2003;110(5):517-36.

64. Levin EC, Acharya NK, Han M, Zavareh SB, Sedeyn JC, Venkataraman V, et al. Brain-reactive autoantibodies are nearly ubiquitous in human sera and may be linked to pathology in the context of blood-brain barrier breakdown. Brain research. 2010;1345:221-32.

65. Diamond B, Honig G, Mader S, Brimberg L, Volpe BT. Brain-reactive antibodies and disease. Annual review of immunology. 2013;31:345-85.

66. Calderon-Garciduenas L, D'Angiulli A, Kulesza RJ, Torres-Jardon R, Osnaya N, Romero L, et al. Air pollution is associated with brainstem auditory nuclei pathology and delayed brainstem auditory evoked potentials. International journal of developmental neuroscience : the official journal of the International Society for Developmental Neuroscience. 2011;29(4):365-75.

67. Braak H, Del Tredici K, Rub U, de Vos RA, Jansen Steur EN, Braak E. Staging of brain pathology related to sporadic Parkinson's disease. Neurobiology of aging. 2003;24(2):197-211.

$68 . \quad$ Del Tredici K, Braak H. Dysfunction of the locus coeruleus-norepinephrine system and related circuitry in Parkinson's disease-related dementia. Journal of neurology, neurosurgery, and psychiatry. 2013;84(7):774-83.

69. Meissner WG. When does Parkinson's disease begin? From prodromal disease to motor signs. Revue neurologique. 2012;168(11):809-14.

70. Tison F, Meissner WG. Movement disorders in 2013: diagnosing and treating PD-the earlier the better? Nature reviews Neurology. 2014;10(2):65-6.

71. Prediger RD, Aguiar AS, Jr., Matheus FC, Walz R, Antoury L, Raisman-Vozari R, et al. Intranasal administration of neurotoxicants in animals: support for the olfactory vector hypothesis of Parkinson's disease. Neurotoxicity research. 2012;21(1):90-116.

72. Braak H, Del Tredici K. Where, when, and in what form does sporadic Alzheimer's disease begin? Current opinion in neurology. 2012;25(6):708-14.

73. Braak H, Thal DR, Ghebremedhin E, Del Tredici K. Stages of the pathologic process in Alzheimer disease: age categories from 1 to 100 years. Journal of neuropathology and experimental neurology. 2011;70(11):960-9.

74. Qin L, Wu X, Block ML, Liu Y, Breese GR, Hong JS, et al. Systemic LPS causes chronic neuroinflammation and progressive neurodegeneration. Glia. 2007;55(5):453-62.

75. Hartz AM, Bauer B, Block ML, Hong JS, Miller DS. Diesel exhaust particles induce oxidative stress, proinflammatory signaling, and P-glycoprotein up-regulation at the blood-brain barrier. FASEB journal : official publication of the Federation of American Societies for Experimental Biology. 2008;22(8):2723-33.

76. MohanKumar SM, Campbell A, Block M, Veronesi B. Particulate matter, oxidative stress and neurotoxicity. Neurotoxicology. 2008;29(3):479-88.

77. Wang JZ, Xia YY, Grundke-lqbal I, Iqbal K. Abnormal hyperphosphorylation of tau: sites, regulation, and molecular mechanism of neurofibrillary degeneration. Journal of Alzheimer's disease : JAD. 2013;33 Suppl 1:S123-39.

78. Avila J, Leon-Espinosa G, Garcia E, Garcia-Escudero V, Hernandez F, Defelipe J. Tau Phosphorylation by GSK3 in Different Conditions. International journal of Alzheimer's disease. 2012;2012:578373. 

disease: pathogen or protector? Trends in molecular medicine. 2005;11(4):164-9.

80. Buee L, Troquier L, Burnouf S, Belarbi K, Van der Jeugd A, Ahmed T, et al. From tau phosphorylation to tau aggregation: what about neuronal death? Biochemical Society transactions. 2010;38(4):967-72.

81. Hernandez F, Avila J. Intra- and extracellular protein interactions with tau. Current Alzheimer research. 2010;7(8):670-6.

82. Spillantini MG, Goedert M. Tau pathology and neurodegeneration. The Lancet Neurology. 2013;12(6):609-22.

83. Clavaguera F, Hench J, Goedert M, Tolnay M. Invited review: Prion-like transmission and spreading of tau pathology. Neuropathology and applied neurobiology. 2015;41(1):47-58.

84. Goedert M, Falcon B, Clavaguera F, Tolnay M. Prion-like mechanisms in the pathogenesis of tauopathies and synucleinopathies. Current neurology and neuroscience reports. 2014;14(11):495.

85. Jung CR, Lin YT, Hwang BF. Ozone, particulate matter, and newly diagnosed Alzheimer's disease: a population-based cohort study in Taiwan. Journal of Alzheimer's disease : JAD. 2015;44(2):573-

84.

86. Bonda DJ, Wang X, Lee HG, Smith MA, Perry G, Zhu X. Neuronal failure in Alzheimer's disease: a view through the oxidative stress looking-glass. Neuroscience bulletin. 2014;30(2):243-52.

87. Silva BA, Breydo L, Fink AL, Uversky VN. Agrochemicals, alpha-synuclein, and Parkinson's disease. Molecular neurobiology. 2013;47(2):598-612.

88. Baltazar MT, Dinis-Oliveira RJ, de Lourdes Bastos M, Tsatsakis AM, Duarte JA, Carvalho F. Pesticides exposure as etiological factors of Parkinson's disease and other neurodegenerative diseases--a mechanistic approach. Toxicology letters. 2014;230(2):85-103.

89. Palma JA, Kaufmann H. Autonomic disorders predicting Parkinson's disease. Parkinsonism \& related disorders. 2014;20 Suppl 1:S94-8.

90. Anang JB, Gagnon JF, Bertrand JA, Romenets SR, Latreille V, Panisset M, et al. Predictors of dementia in Parkinson disease: a prospective cohort study. Neurology. 2014;83(14):1253-60.

91. Xia J, Rocke DM, Perry G, Ray M. Differential network analyses of Alzheimer's disease identify early events in Alzheimer's disease pathology. International journal of Alzheimer's disease. 2014;2014:721453.

92. Rodrigues R, Petersen RB, Perry G. Parallels between major depressive disorder and Alzheimer's disease: role of oxidative stress and genetic vulnerability. Cellular and molecular neurobiology. 2014;34(7):925-49.

93. Ascherio A, Munger KL. Environmental risk factors for multiple sclerosis. Part II: Noninfectious factors. Annals of neurology. 2007;61(6):504-13.

94. Ascherio A, Munger KL. Environmental risk factors for multiple sclerosis. Part I: the role of infection. Annals of neurology. 2007;61(4):288-99.

95. Riise T, Nortvedt MW, Ascherio A. Smoking is a risk factor for multiple sclerosis. Neurology. 2003;61(8):1122-4.

96. Mikaeloff $Y$, Caridade G, Tardieu M, Suissa S. Parental smoking at home and the risk of childhood-onset multiple sclerosis in children. Brain. 2007;130(10):2589-95.

97. Hernán MA, Oleky MJ, Ascherio A. Cigarette Smoking and Incidence of Multiple Sclerosis. American journal of epidemiology. 2001;154(1):69-74.

98. Simpson S, Blizzard L, Otahal P, Van der Mei I, Taylor B. Latitude is significantly associated with the prevalence of multiple sclerosis: a meta-analysis. Journal of Neurology, Neurosurgery \& Psychiatry. 2011:jnnp. 2011.240432.

99. Soilu-Hanninen M, Laaksonen M, Laitinen I, Eralinna JP, Lilius EM, Mononen I. A longitudinal study of serum 25-hydroxyvitamin $D$ and intact parathyroid hormone levels indicate the importance of vitamin $\mathrm{D}$ and calcium homeostasis regulation in multiple sclerosis. Journal of neurology, neurosurgery, and psychiatry. 2008;79(2):152-7.

100. Munger KL, Zhang S, O'reilly E, Hernan M, Olek M, Willett W, et al. Vitamin D intake and incidence of multiple sclerosis. Neurology. 2004;62(1):60-5.

101. Munger KL, Levin LI, Hollis BW, Howard NS, Ascherio A. Serum 25-hydroxyvitamin d levels and risk of multiple sclerosis. JAMA. 2006;296(23):2832-8. 
102.

Hosseinpanah F, Sima H, Heibatollahi M, Moghbel N, Asefzade S, Azizi F. The effects of air pollution on vitamin D status in healthy women: a cross sectional study. BMC Public Health. 2010;10(1):519.

103. Agarwal KS, Mughal MZ, Upadhyay P, Berry JL, Mawer EB, Puliyel JM. The impact of atmospheric pollution on vitamin D status of infants and toddlers in Delhi, India. Archives of disease in childhood. 2002;87(2):111-3.

104. Baiz N, Dargent-Molina P, Wark JD, Souberbielle JC, Slama R, Annesi-Maesano I, et al. Gestational exposure to urban air pollution related to a decrease in cord blood vitamin d levels. The Journal of clinical endocrinology and metabolism. 2012;97(11):4087-95.

105. Manicourt DH, Devogelaer JP. Urban tropospheric ozone increases the prevalence of vitamin D deficiency among Belgian postmenopausal women with outdoor activities during summer. The Journal of clinical endocrinology and metabolism. 2008;93(10):3893-9.

106. Calderon-Garciduenas L, Azzarelli B, Acuna H, Garcia R, Gambling TM, Osnaya N, et al. Air pollution and brain damage. Toxicologic pathology. 2002;30(3):373-89.

107. Oikonen $\mathrm{M}$, Laaksonen $\mathrm{M}$, Laippala $\mathrm{P}$, Oksaranta $\mathrm{O}$, Lilius EM, Lindgren $\mathrm{S}$, et al. Ambient air quality and occurrence of multiple sclerosis relapse. Neuroepidemiology. 2003;22(1):95-9.

108. Gregory AC, 2nd, Shendell DG, Okosun IS, Gieseker KE. Multiple Sclerosis disease distribution and potential impact of environmental air pollutants in Georgia. The Science of the total environment. 2008;396(1):42-51.

109. Heydarpour P, Amini H, Khoshkish S, Seidkhani H, Sahraian MA, Yunesian M. Potential Impact of Air Pollution on Multiple Sclerosis in Tehran, Iran. Neuroepidemiology. 2014;43(3-4):233-8.

110. SAEI M, HOLAKOUIE-NAIENI K, MOSTAFAVI E, SAHRAIAN MA, MAHMOODI M, MANSOURNIA MA, et al. Spatial Analysis of Multiple Sclerosis Disease in Tehran Metro-poli-tan Zone, Iran, 2001- 2012. Iranian Journal of Public Health. 2014;43(5):621-9.

111. Mehrpour M, Shams-hosseini NS, Rezaali S, Sahraian MA, Taki S. Effect of Air Pollutant Markers on Multiple Sclerosis Relapses. Iranian Journal of Public Health. 2013;42(10):1167-73.

112. Vojinoviü Slobodan SD, Lukiü Stevo, Saviü Ljiljana, Vojinoviü Jelena. Disease relapses in multiple sclerosis can be influenced by air pollution and climate seasonal conditions. Vojnosanit Pregl. 2015;72(1):44-9.

113. Oikonen MK, Eralinna JP. Beta-interferon protects multiple sclerosis patients against enhanced susceptibility to infections caused by poor air quality. Neuroepidemiology. 2008;30(1):13-9.

114. Campbell A, Oldham M, Becaria A, Bondy SC, Meacher D, Sioutas C, et al. Particulate matter in polluted air may increase biomarkers of inflammation in mouse brain. Neurotoxicology. 2005;26(1):133-40. 115. Kleinman MT, Araujo JA, Nel A, Sioutas C, Campbell A, Cong PQ, et al. Inhaled ultrafine particulate matter affects CNS inflammatory processes and may act via MAP kinase signaling pathways. Toxicology letters. 2008;178(2):127-30.

116. Gerlofs-Nijland ME, van Berlo D, Cassee FR, Schins RP, Wang K, Campbell A. Effect of prolonged exposure to diesel engine exhaust on proinflammatory markers in different regions of the rat brain. Particle and fibre toxicology. 2010;7:12.

117. Agency EE. Safeguarding people from environmental risks to health; The European environment - state and outlook 2015: synthesis report. Copenhagen: 2015. 